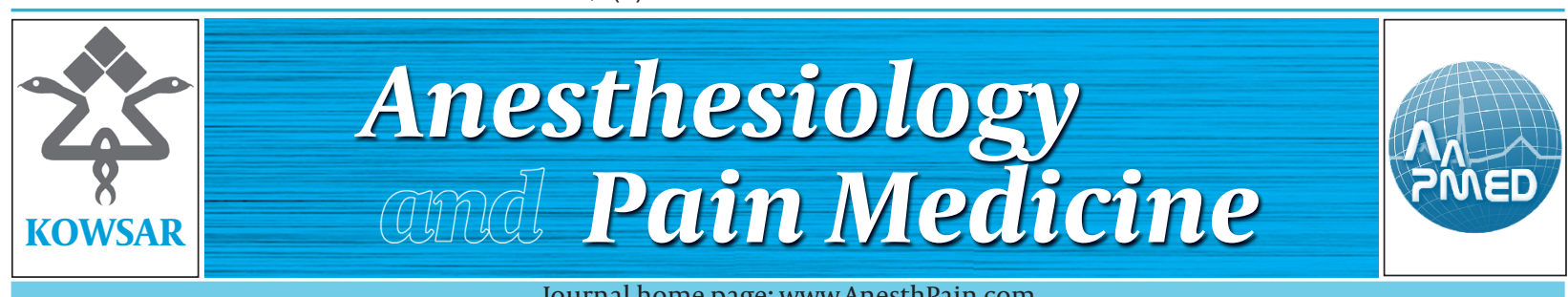

\title{
Intrathecal Injection of Amitriptyline and Doxepin for Spinal Anesthesia in Animal Studies
}

\author{
G. Ulufer Sivrikaya ${ }^{1^{*}}$ \\ ${ }^{1}$ Department of Second Anesthesiology and Reanimation, Sisli Etfal Training and Research Hospital, Istanbul, Turkey
}

A R T I C L E I N F O

Article Type:

Letter to Editor

Article history:

Received:18 Aug 2011

Revised: 20 Aug 2011

Accepted: 25 Aug 2011

\section{Keywords:}

Spinal anesthesia

Amitriptyline

Doxepin

Please cite this paper as:

Sivrikaya GU. Intrathecal Injection of Amitriptyline and Doxepin for Spinal Anesthesia in Animal Studies. Anesth Pain. 2011;1(2):1156.

DOI:10.5812/kowsar.22287523.2127

Copyright $\odot 2011$, ISRAPM, Published by Kowsar Corp.

served at multiple sites.

Antidepressants belonging to a same class also show difference in the intensities of pharmacological actions, some accounting for differential actions and side effects, similar to the findings of amitryptyline and doxepin reported by Alebouyeh et al. Tricyclic antidepressants (TCAs) have very different efficacy as local anesthetics in vivo (3). Among various TCAs, amitriptyline and doxepin have been studied as local anesthetics in most studies. Chen YW et al. evaluated the spinal anesthetic effect of various TCAs after a single intrathecal injection (4). In this study, the effects of 9 TCAs, including amitriptyline and doxepin, and 3 traditional local anesthetics (bupivacaine, lidocaine, and mepivacaine) were evaluated in rats. The results showed that intrathecal amitriptyline had a more potent and longer duration of spinal anesthetic effect than bupivacaine (under a given concentration of $5 \mathrm{mM}$ ), whereas the potency of other TCAs was similar to or less than that of bupivacaine.

Although meta-analyses on the maximum allowable dose for intrathecal injection of these drugs have not been performed, several studies have reported the administration of these drugs in different doses. The study performed by Alebouyeh et al. has contributed to these findings; In a study performed by Cerda et al. , intrathe-

\footnotetext{
* Corresponding author: G. Ulufer Sivrikaya, Department of Second Anesthesiology and Reanimation, Sisli Etfal Training and Research Hospital, Kucukbahce Sk. No. 28/34 Sisli, P O. Box: 34363, Istanbul, Turkey. Tel: +905322924173, Fax:+90-2122472576,E-mail: ulufers@gmail.com

DOI: 10.5812 /kowsar.22287523.2127

Copyright $\odot 2011$, ISRAPM, Published by Kowsar Corp.
} 
cal injection of varying doses of amitriptyline (0. 25, 1, and $5 \mathrm{mg}$ ) in sheep using low thoracic catheters did not significantly affect spinal cord blood flow or hemodynamic variables (5). In another study, amitriptyline was administered intrathecally at doses of 25,50 , and $100 \mu \mathrm{g} /$ rat to investigate the effect on carrageenan-induced paw edema in rats and no side effects were observed (6). Sudoh et al. used a route of administration different from intrathecal administration; they administered amitryptyline and doxepin $5 \mathrm{mM}$ as a single injection via the sciatic notch of rats (3) and administered doxepin 2. 5, 5. 0, and $10 \mathrm{mM}$ in a rat sciatic nerve model (7). In the latter case, possible morphological alterations were assessed by light microscopic examination in the cross-sections of the sciatic nerves; there was no evidence of neurotoxicity, and they concluded that doxepin seemed to be nontoxic to peripheral nerves at concentrations up to $10 \mathrm{mM}$.

However, a number of studies have shown concentration-dependent toxicity when these drugs are applied to the peripheral nerve or are administered intrathecally (8-10). Safety is an important aspect of intrathecal administration of novel agents; safety of administration can be evaluated by determining not only the potential effect on function (e. g. , motor, sensory, autonomic) but also changes in spinal morphology. In another study by Sudoh et al. , spinal blockade after intrathecal administration of various concentrations of amitriptyline in a fixed high volume and histopathologic changes in the spinal cord were evaluated (9). They administered $100 \mu \mathrm{L}$ of 5 , $10,15.9$ (0.5\%), 25,50 , or $100 \mathrm{mmol} / \mathrm{L}$ amitriptyline hydrochloride solution intrathecally to rats. At doses of 50 and $100 \mathrm{mmol} / \mathrm{L}$, many rats did not completely recover from spinal block. In addition, severe histopathologic changes were seen in the spinal root section of animals injected with concentrations higher than $25 \mathrm{mmol} / \mathrm{L}$ amitriptyline. Intrathecal administration of amitriptyline at high doses is not recommended because it might cause irreversible neurologic deficit. In a study by Gerner et al. , 60 $\mu \mathrm{L}$ of doxepin at 10,20 , and $50 \mathrm{mM}$ was injected through intrathecal catheters implanted in the lumbar region of rats (11). Their results showed that intrathecal doxepin most likely has a very narrow therapeutic range approximately 10-20 mM for complete blockade and higher concentrations are likely to be neurotoxic. In this study, neurotoxicity, defined as persistent neurological deficit, was observed at $50 \mathrm{mM}$.

The adverse-effects of antidepressants are primarily related to their pharmacological properties. Some antidepressants have cardiotoxic side effects such as blockade of alpha 1-noradrenergic receptors, which lead to orthostatic hypotension and tachycardia. TCAs also have type 1 antiarrhythmic action and are potent inhibitors of sodium channels (2). Doxepin has lesser cardiotoxicity than other TCAs (11). I agree with the findings reported by Alebouyeh et al. that cardiotoxicity might be the most likely reason of deaths.

Although TCAs, mainly amitriptyline, followed by doxepin, appear to be more effective than bupivacaine in inducing spinal blockade, their poor tolerability profile (discussed below) and need for careful dose titration (because of a low therapeutic index) are major limitations of administration of these drugs.

In conclusion, more preclinical toxicity studies are necessary before introducing intrathecal amitriptyline and doxepin for use in humans. Studies to assess the safety and the therapeutic range of intrathecal application of these drugs will be very useful clinically.

\section{Financial Disclosure}

None declared.

\section{References}

1. Alebouyeh MR, Imani F, Rahimzadeh P, Faiz SHR. Evaluation of the efficacy of intrathecal injection of amitriptyline and doxepin in spinal anesthesia in comparison with bupivacaine in rats. Anesth Pain. 2011;1(1):15-9.

2. Dharmshaktu P, Tayal V, Singh Kalra B. Efficacy of Antidepressants as Analgesics: A Review. JClin Pharmacol. 2007:[Epub ahead of print].

3. Sudoh Y, Cahoon EE, Gerner P, Wang GK. Tricyclic antidepressants as long-acting local anesthetics. Pain. 2003;103(1-2):49-55.

4. Chen YW, Huang KL, Liu SY, Tzeng JI, Chu KS, Lin MT, et al. Intrathecal tri-cyclic antidepressants produce spinal anesthesia. Pain. 2004;112(1-2):106-12.

5. Cerda SE, Tong C, Deal DD, Eisenach JC. A physiologic assessment of intrathecal amitriptyline in sheep. Anesthesiology. 1997;86(5):1094-103.

6. Hajhashemi V, Sadeghi H, Minaiyan M, Movahedian A, Talebi A. The role of central mechanisms in the anti-inflammatory effect of amitriptyline on carrageenan-induced paw edema in rats. Clinics (Sao Paulo). 2010;65(11):1183-7.

7. Sudoh Y, Cahoon EE, De Girolami U, Wang GK. Local anesthetic properties of a novel derivative, N-methyl doxepin, versus doxepin and bupivacaine. Anesth Analg. 2004;98(3):672-6. table of contents.

8. Estebe JP, Myers RR. Amitriptyline neurotoxicity: dose-related pathology after topical application to rat sciatic nerve. Anesthesiology. 2004;100(6):1519-25.

9. Sudoh Y, Desai SP, Haderer AE, Sudoh S, Gerner P, Anthony DC, et al. Neurologic and histopathologic evaluation after high-volume intrathecal amitriptyline. Reg Anesth Pain. 2004;29(5):43440.

10. Barnet CS, Louis DN, Kohane DS. Tissue injury from tricyclic antidepressants used as local anesthetics. Anesth Analg. 2005;101(6):1838-43.

11. Gerner P, Srinivasa V, Zizza AM, Zhuang ZY, Luo S, Zurakowski D, et al. Doxepin by topical application and intrathecal route in rats. Anesth Analg. 2006;102(1):283-7. 